\title{
Element Research of Modern Education Theory in Martial Arts
}

\author{
Zhu Xiong \\ Wuhan Sports University, Wuhan, Hubei, China
}

\begin{abstract}
Keywords: Contemporary martial arts; Education ideology; Elements
\end{abstract}
\begin{abstract}
The contemporary martial arts education ideological means that in the process of modern martial arts, to use the ideas which is contained in the martial arts with people (especially the thought of martial arts player) to make a interact in a purposeful and planned way, to make its cogitation developed along with a track which is contained in the martial arts, and as the guiding ideology of martial arts activities. Contemporary Wushu education ideological elements combined with fitness education thought, tournament education thought, subject education thought, moral education thought, culture education thought and profession education thought. And these elements become the core of contemporary martial arts education ideological have the reason of its inherent. Hold the character of contemporary martial arts education ideological is a key to recognize the development of martial arts.
\end{abstract}

\section{Introduction}

Chinese traditional sports culture reflects all forms of physical activity, sportsmanship and national sports system how they thinking about, cultural awareness, spiritual values and so on by creating and preserving, by participating in long-term production and life practice. In the process of evolution of the Chinese martial arts have a long history; it's a splendid pearl, which is the Chinese excellent traditional culture and national spirit. It is very important to promote the development of martial arts and inherit the ideas of martial arts culture in any period of history. At the moment, however, we regret that the spread of martial arts rely too much on film and television media and left to the audience a deep impression on strike technology, and it is inappropriate that focus on simple martial arts repertoire project exercises. One the one hand, the pursuit of visual sense misled the martial arts forms of reality; on the other hand, martial arts repertoire exercises can't catch the core development of martial arts and it's too difficult, unpractical and boring too prevents people's passion on martial arts.

In April 2004, the Central Propaganda Department and the Ministry of Education jointly issued "Primary and Secondary Schools to Carry Forward and Cultivate the National Spirit Education Implementation Outline”. It is demanding to increase martial arts class in primary and secondary schools, to improve the status of martial arts education in school, which purpose is to educate teenagers to inherit and carry forward the traditional culture and promote the development of modern martial arts. After more than ten years of practice, martial arts have entered the classroom; martial arts education had generally accepted by teenagers, but as a fundamental guarantee of the development of martial arts, martial arts education work in schools of various levels are faced with severe situation. Experts have written the concern about the development of current martial arts, pointing out that the martial arts into school is progress in the development of martial arts, regarding martial arts as a sport, ${ }^{[1]}$ which cannot meet its cultural value, cannot catch martial arts education thought. It is hard to achieve the purpose of carrying forward the traditional culture. Therefore, this article tries to analyze education ideological elements from the contemporary martial arts sport, in order to provide a new understanding for the development of martial arts.

\section{The contemporary martial arts fitness education thought}

\subsection{As the cause of the elements}

The fitness function of martial arts have had a long term, it had recognized and put into practice, which is determined by the properties of the martial arts as a sport .The fitness function of martial arts is not same as the general sports, apart from its role of physical fitness, it also has more features 
in the terms of health care, resistance to disease, health maintenance and so on. First of all, martial arts is an intense stress adaptive sport. The basic action of martial arts: kick, hit, throw, take, stand, jump, and continuous movement time decision martial arts is a high strength, anaerobic endurance sports. The body can produce strong stress response from it, and it helps to improve the movement of anti-hypoxia physical ability. Secondly, the martial arts is a sport emphasis on internally and externally. As the old saying: practicing tendons, bones and skin outside, training fine, gas and spirit inside, it reflects that martial arts is different from other sports which only focus on the muscle and physical exercise. In addition, we have to emphasize the special relationship between martial arts and ancient Chinese guide health preservation when talking about the fitness value of martial arts. Ancient Chinese guide health preservation emphasis on the guidance of breathing, pays attention to the natural environment of practicing, deposits the stale and bringing into the fresh, exchange method of preserving one's health with the nature of the material energy, it is well used in the martial arts, which to promote health, health care, resist disease has a unique role. Finally, the martial arts is a thriving contented sport and has various forms. It is not only has routine exercises, as well as exercises against skill. Routine exercise is divided into boxing, equipment, single and multiple training and there are a variety of boxing and many genres. Different exercise content and forms of exercise have a wide range of effects on human health; it also plays a complementary role. With contemporary martial arts as an important military means withdrawing from the historical stage, the fitness function becomes the main social function of martial arts. So, martial arts fitness education thought inevitably becomes the contemporary martial arts important education thought.

\subsection{The main performances}

The fitness education thought of contemporary martial arts is mainly embodied: first of all, the concept of martial arts fitness updates education ideas .Wang Zongyue, Qing dynasty wrote in " 13 Potential Songs" said very clearly: "Deducing what is the meaning of practice martial arts, that is make practitioners longevity."[2] It indicates that the social function of martial arts in the Qing dynasty had undergone significant changes. The ultimate purpose of learning martial arts is to "prolong life". At present, martial arts fitness education thought should be clear to serve the national fitness project. The second is the contemporary martial arts fitness practices education thought. Martial arts fitness can improve the sport ability of the body and cardiovascular function, strengthen body, promote health, resist disease and prolong life. At the same time, because martial arts is a special sport, which is rich in content and have different forms. Different forms of exercise suit for different fitness crowd. When selecting martial arts as fitness, people should choose appropriate forms of exercise according to their own physical quality. Such fierce confrontation projects and long boxing sports need higher requirements for physical fitness, more suitable for teenagers; the rhythm of Tai chi and tai chi sword is slow and flat, more suitable for the older age fitness crowds. Finally, martial arts fitness takes fully advantage of the space and time of education thoughts. Martial arts fitness is less affected by time, environment and space. For martial arts adjust measures to local conditions, which is different from person to person in fitness activities provided

a broad space. People can choose according to the need of fitness, personal practice, the two single man prepared or collective exercise, can also assign the corresponding music and instruments to improve training effect.

\section{The contemporary martial arts education thought}

\subsection{As the cause of the elements}

The competitive value of the martial arts is the basic content and the necessity of the development of martial arts. It illustrates that competition is the necessary means of martial arts technology improvement and development. At the beginning of the founding of new China, different performances and competitions of martial arts had played a great role in promoting and developing of martial arts, which makes the development of martial arts step into a fast track. Although over a period of time, the development of martial arts has stalled. But in mid and late 80s, the development of martial arts had back to life. Domestic martial arts community was emerging, 
and the competition of martial arts at various levels had become increasingly active, which had given rise to "martial arts", "tai chi chuan". Entered the 21st century, with the accelerating process of globalization, the traditional martial arts was defined as the national sports. That rack of development must be an integral part of competitive sports to embark on the road. Martial arts and the modern sports and international sports "standards" were the highest level of modern athletic sports closing to the Olympic movement. So, the modern athletics martial arts must become an important part of martial arts development.

\subsection{The main performances}

Contemporary martial arts education thought mainly includes: first, the competition education thought of fair, just and open under the modern competitive consciousness. The contemporary competitive martial arts are in the process of seeking their own development, they must be attached many common features of modern competitive sports. In the form of performance, competitive martial arts should reflect modern competitive sports fair, just, open and competitive and view and admire a gender to comply with the consistency of the Olympic spirit and meet the demands of social psychology of market audiences. On the rules of competition, competitive martial arts should reflect maneuverability; award winner must have uniform quantitative criteria. This requires the development of competitive martial arts inevitable to give up some of the traditional and ethnic elements, draw on cultural elements from other nations at the same time, to make competitive martial arts have of both national and global characteristics. Second, the contemporary scientific martial arts involved in the education of modern sports thought. Contemporary development in competitive martial arts must have its own characteristics for sport, and to be on behalf of their own national characteristics reflected movement technology and form In order to reflect the profound Chinese martial arts. While the Chinese martial arts genre is numerous, and has complex system. Any kind of martial arts project can't represent the whole picture of Chinese martial arts, which determines the richness of the modern athletics martial arts events and contemporary martial arts competition projects can be creative. They can't carry out activities in the traditional martial arts competition inherent in martial arts. Also we have to consider the ethnic characteristics of martial arts in the development .So, which project is more representative, reflects national character, suitable for global promotion, which projects should not be developed into the contemporary martial arts competitions, this is a question worthy of in-depth discussion. Third, modern athletics martial arts should carry forward the education thoughts of patriotism and national spirit. The Chinese traditional martial arts in a certain sense, is to develop Chinese descendants concept of patriotism and national spirit home. Modern competitive martial arts inherited and developed traditional Chinese martial arts, standing in the world with a new gesture of competitive sports .It must shoulder to carry forward the spirit of the Chinese sports, cultivate citizens national concept and the responsibility of patriotic feeling. In the competitive arena, the contemporary competitive martial arts need to promote the charm of Chinese culture, to show the achievements of Chinese civilization for thousands of years, to embody the essence of Chinese sports spirit, to display the Chinese spirit in order to stimulate national pride and patriotism of the Chinese people.

\section{The contemporary martial arts discipline education thought}

\subsection{As the cause of the elements}

The combination of martial arts into school and modern sports and modern education ideas laid the foundation for the development of contemporary martial arts discipline. People understanding of martial arts and movement rules, martial arts disciplinary position for the sports and cultural crossdisciplinary is accord with the characteristics of martial arts discipline development. ${ }^{[3]}$ When martial was defined as sport, it is a sport. The independence of the martial arts sports science determines the martial arts is a branch of sports science disciplines. When martial arts defined as a culture, it is considered from its literature, history and philosophy features, more emphasis on this aspect of the humanities. The close contact with the history and philosophy of martial arts, determines the value of independent existence of martial arts science. The scientific development of 
martial arts, on the one hand it can be training more professionals, on the other hand is conducive to wealth and inheritance martial arts culture.

\subsection{The main performances}

Contemporary martial arts disciplinary education thought mainly manifests: first, the martial arts sport determines Wushu is a sport education thought. Martial arts is a sport, and physical properties are inherent attributes of martial arts. After the founding of new China, Wushu was formally listed in the sports category. Although the nature of martial arts had a scholarly contention, after the 80s, the martial arts session agrees that martial arts belong to the Chinese nation traditional sports project with physical attributes ${ }^{[4]}$.Second, the martial arts discipline inheres nationality and cultural educational ideology. The biggest difference between martial arts sport and general sport is inherent national characteristics and cultural characteristics of martial arts .It was born from the traditional culture, fully absorbed Confucianism, Taoism, Buddhism, military and other schools of thought of the traditional culture, at the same time with Chinese traditional philosophy, aesthetics, law, medicine, religion and other cultural color, is a diverse collection of the traditional culture of China. Talking about martial arts from any angle, we have to refer to the traditional culture features of martial arts .It can be said, the ethnic traditional culture characteristics of martial arts is the biggest characteristic of martial arts discipline, also is the basis for the development of martial arts disciplines. To inherit and carry forward the excellent traditional culture is bound to become a main task of the development of martial art. Third, the historical origins of martial arts movement determine the historical features of martial arts discipline .Contemporary martial arts are the reproduction of traditional martial arts. Laying the foundation for the development of the martial arts discipline is indispensable to mine the martial arts historical data and textual research the traditional martial arts. Many traditional martial arts lost in succession, it is regrettable development of martial arts disciplines; it gratifies people that many traditional historical data of martial arts are found in archaeological, which provides strong evidence for historical development of martial arts .Every bit of the discovery of martial arts history is to enrich and develop martial arts discipline. Therefore, the study of contemporary martial art is inseparable from the traditional martial arts collation and research. Fourth, the ideological source of the martial arts discipline determines martial arts and philosophy of ancient China are closely related. Both traditional Chinese martial arts and modern competitive martial arts embody the basic connotation of the ancient Chinese philosophy thought. On the value of expression, martial arts reflects the view of Chinese Confucian culture on practice martial arts for healthy, Taoist Culture on practice martial arts for Regimen, Buddhism culture on self-defense and military culture on protect country. In the aspect of culture, martial arts always reflect the traditional elements of ancient Chinese culture, such as "nature and humanity", "Yin and Yang five lines", "impartial", "golden mean" and other traditional aesthetic," offensive and defensive retreat," "full force". Martial arts as an interdisciplinary combined sport and humanities, is bound to pay attention to the development of martial arts in the body, literature, history, philosophy. At present, martial arts discipline development skills teaching and heavies oneway development, but lights discipline theory research and interdisciplinary collaborative innovation hindered the development of martial arts.

\section{The contemporary martial arts morality education thought}

\subsection{As the cause of the elements}

Morality of martial arts is an important cultural phenomenon in martial arts." learn moral before learn martial arts", "respect the teacher and his teachings", "serve our country with loyalty" and other traditional martial arts ethics in martial arts lineage play an important role in the process of development. There must be some inherent cause why practitioners or teachers value the moral of martial arts. On the one hand, in ancient times, martial arts is a kind of blow technology .It has the function of getting rid of the crimes and protect the victim, but also has the social harm of deceiving the strong bullying the weak and violating a ban." Morality of martial arts is more important than martial arts itself " is the guarantee for practitioners to develop to the right direction after they 
succeed in martial arts, it is also the important reason why there are so many ancient outlaw heroes recorded in historical records. On the other hand, Chinese martial arts branch numerous, and very focused on sectarianism. Huang Baijia wrote in the "within the family blows": "There are five kinds of people will not be taught". This is a protection of martial arts and also a highly praise of the moral of martial arts. It is the inheritance and maintenance of martial arts ethics for thousands of years makes a high respect for martial arts in contemporary mind. The morality of martial arts is one kind of the professional ethics, is a historical category. It will have different moral standards in different historical periods. To the modern times, with the needs of the development of society, people's moral standards, value orientation has obviously changed. The inherent moral ideas contained in martial arts, and the innovation of traditional moral of martial arts must become an important content of modern martial arts education ideology.

\subsection{The main performances}

Contemporary martial arts moral education ideology is mainly embodied as follows: firstly, cultivate one's morality which can raise the level of people's moral education thought. Traditional moral of martial arts is more emphasized on practitioners' morality, maintaining social justice and dying for the country's patriotic emotion. In the era of modern society, there are new requirements on ethics, martial arts has become a kind of entertainment, fitness activity. Universally accepted martial arts education, the morality of it has become an important tutorial that people raise the level of moral. Secondly, promote the education thoughts of social harmony via it. At the social level, the morality of martial arts has become a social fashion from safeguard judicial justice to the pursuit of ritual and trustworthy, the heavy righteousness light benefit, humble love and constantly striving .The development of martial arts is helpful to promote social harmony. Thirdly, cultivate the youth patriotism. Martial arts contain a rich value of patriotism and national spirit factor. From the national perspective, we should regard it as an important content of cultivating and shaping the young generation patriotism, national spirit and cultivate the spirit of contemporary youth in China. Now, because people despise the traditional culture, martial arts education function is weakened, so martial arts education workers must draw a great attention.

\section{Contemporary martial arts culture education ideology}

\subsection{As the cause of the elements}

"Martial arts lies in sports, but higher than sports", the main reason for it is that it has the rich connotation of Chinese traditional culture. ${ }^{[5]}$ Separate the relationship between martial arts and Chinese traditional culture, or in other words, the one-sided emphasis on the fitness function of martial arts will lead to the loss of essential characteristics of martial arts and of national identity. Because firstly, it is determined by the cultural inheritance. Martial arts is the essence of traditional culture. On one hand, inheritance and learning martial arts culture is the mission of martial arts culture education. On the other hand, the inheritance of martial arts culture has a great effect in the development of martial arts itself and cultivating the Chinese values and spiritual world. Secondly, it is determined by the education function of martial arts. Martial arts education value has been confirmed in physical education of primary school, middle school and college. Martial arts education is not only a kind of physical education but also a kind of cultural education and ideological education. The value of martial arts education for a generation and a country's education is self-evident. It inherited folk customs and values of a country and a nation in the process of accumulating and learning national culture.

\subsection{The main performances}

The martial arts culture education thoughts mainly performs: first, understand contemporary Wushu education thought from the height of the excellent traditional culture .we must understand and recognize the contemporary martial arts from the excellent traditional culture to inherit and carry forward the contemporary martial arts culture and undertake the responsibility of the young generation. For decades, the experience of development of martial arts tells us that ignoring martial arts culture education, one-sided pursuit of martial arts skills education, will only make the 
development of martial arts off center. Now many people ignore the traditional culture. This is the biggest obstacle encountered in the process of martial arts development, and is also the biggest challenge faced in a nation. If one nation does not have its own culture, just like a person does not have his own belief. So, there is no doubt that it will be replaced by other nation's culture, and lose the national religion. We should work with martial arts culture education as an opportunity to strengthen the education of young generation of ethnic traditional culture. Secondly, give full play to the education of martial arts culture spirit education ideology. Martial arts is a kind of culture, and also a kind of spirit, it is a special "education". Martial arts and the traditional Chinese culture for thousands of years maintain inextricably linked, with the troubled feelings of the Chinese nation has a difficult history to break away. In a number of important historical periods, martial arts not only save the nation from the crisis, but also enhance the national cohesion and cultivate a large number of national heroes. Promoting contemporary martial arts culture, it should inherit the traditional flame, while more important is to play the role of martial arts culture system integrity spirit carrier, and make martial arts culture education to be national culture education. Thirdly, martial arts culture education should reflect the education thought of both physical and mental education. The spread of contemporary martial arts culture education thoughts must be with martial arts skills education. Martial arts culture thought can be experienced, explored, but can't develop in depth without the practice of skills. Though, the phenomenon of one-sided pursuit of technical movement now has reached the highlight, we still have to stress the martial arts skills teaching and imparting martial arts culture thoughts to be the two wheels of the wagon, to keep in pace together.

\section{Conclusions}

Martial arts education thought is the soul of martial arts development. Martial arts education thought integrating into martial arts development will inevitably guide the development of martial arts into the right direction. Perspective from the main body of the development of contemporary martial arts, martial arts fitness education thought, competitive education thought, discipline education thought, moral education thought, cultural education thought are important education thoughts in martial arts, which we must grasp fully and correctly.

\section{References}

[1] Liu Jun, Pixiang Qiu. Martial arts culture education present situation in our country and its education function heritage research [J]. Journal of Shenyang Institute of Physical Education, 2009 (2), PP. 126-128.

[2] WenLi. Introduction to the Chinese martial art [M]. People's sport publishing house, in December 2005 the first edition.

[3]Guoyu Cheng. The attribute of martial arts, culture, art, sports, [J]. Martial arts scientific, 2009 (9),PP. 1-2.

[4]Sangquan $\mathrm{Xi}$, Zhangguo Dong. Reform and opening up 30 years of martial arts education hotspot perspective [J]. Journal of sport, 2009, PP.92-97.

[5]Guoyu Cheng, Guoyu Ting .Cultural Orientation of Contemporary Martial Arts Education [J]. Wuhan Institute of Physical Education, 2009 (6), PP. 69-71. 